\title{
Empirical Evidences in Linking Guanxi, Renqing and Justice Theory: Doing Business in the Great China Area
}

\author{
Lung-Tan $\mathrm{Lu}^{1}$ \\ ${ }^{1}$ Fo Guang University, Taiwan \\ Correspondence: Lung-Tan Lu, Department of Management, Fo Guang University, Taiwan. Tel: \\ 886-03-987-1000. E-mail: ltlu@ mail.fgu.edu.tw
}

Received: May 1, 2015

Accepted: June 16, 2015

Online Published: June 25, 2015

doi:10.5539/ibr.v8n7p138

URL: http://dx.doi.org/10.5539/ibr.v8n7p138

\begin{abstract}
This paper utilizes two conceptual frameworks, on the foundation of Hwang's (1987) model and the Justice Theory. It is suggested that businessperson may search for or reinforce Guanxi (tie) by three types of social ties, instrumental, mixed, and expressive. Therefore, resource allocators in Chinese society may deal out their powers to others with varied social ties. This study examines the relationships among the three types of social ties and Renqing giving and returning. Data collected form questionnaires completed by 190 Japanese expatriates in Taiwan. The findings are as follows: (1) businessperson with instrumental Guanxi will apply the equity rule, which excludes Renqing giving and returning; (2) businessperson with mixed Guanxi will use the equality rule, which will request moderate Renqing giving and returning; (3) businessperson with expressive Guanxi will apply the need rule, which will request strong Renqing giving and returning. Managerial implications are discussed in the final section.
\end{abstract}

Keywords: Guanxi, Renqing, justice theory

\section{Introduction}

This paper applies two conceptual frameworks, on the basis of Hwang's (1987) model and the Justice Theory. Lu (2012) developed a framework in linking the three types of social ties and Renqing giving and returning. It is considered that the Hwang's (1987) model represents not only behavioral models of Chinese businessmen, but also broad models for demonstrating the process of business interactions in East Asia.

This paper is structured as follows. First, we give a brief review of Justice Theory, which includes three rules: (1) equity, (2) equality, and (3) need. Second, we discusse Guanxi, which is divided into three types: (1) expressive, (2) mixed, and (3) instrumental (Hwang, 1987). Third, we examine the relationships among the three types of social ties and Renqing giving and returning. Data collected form questionnaires completed by 190 Japanese expatriates in Taiwan. In the following section, the research methods are presented. The forth section shows the results. This paper discusses what Renqing is and it's giving and taking in Chinese business culture in the Great Chinese Area in the final section (Yan, 1996).

\section{Guanxi, Renqing and Justice Theory}

Justice Theory refer to a person's reaction of a benefit obligates the other party to give in return the favor (Goudner, 1960). Individuals in societies exchange or allocate social resources by the three rules. First, equity rule offers that people in society should be rewarded for their givings. Second, equality rule states that all citizens should contribute to benefits and losses equally not considering of the amount to which, if at all, they actually contribute to the society. Finally, need rule conserve that the sharing of benefits in society should consider each individual's practical needs without considering their actual contributions (Hwang, 1987).

Guanxi is an essential Chinese word with multipart thoughts and has been studied by academics in the field of social sciences (Hwang, 1987; Luo, 1997; Tsang, 1998; Wong \& Chan, 1999; Yang, 1994, 2002; Lu, 2012). Anthropologist Fei Xiaotong proposed the Chaxu mode in 1948 to clarify the interactive relationships among the Chinese. He argued that the Chinese typically exercise a diverse standard to treat people with different Guanxi (tie) (Fei, 1992). He suggested that Chinese classify people around them into three groups in mind. First, family members consist of close kinship such as brother (sister), uncle and spouse's brother (sister). Second, in-group persons enclose classmates, co-workers, and neighbor someone you know for a period of time. Finally, 
out-group persons include strangers and (or) somebody you know just for days (Yang, 1994; Tsui \& Farth, 1997, Leung et al., 2008).

In traditional Chinese society, social relationships are like ripples. There are lots of circles from a Chinese within his or her society. If we take the ripple as three circles, the inner circle will be his or her family. Individuals within this circle use the need rule. The middle circle includes relatives, classmates, neighbors, and close friends, all of whom use the equality rule to indulgence each other. The outside circle contains strangers, to whom the equality rule is related. For the Chinese, the equality rule applies only to strangers.

It is suggested Guanxi (tie) can be segregated into three types: (1) expressive, (2) mixed, and (3) instrumental, each of which we will deem in the context of their relationship with the Justice Theory Hwang (1987). Expressive Guanxi (tie) is a long-term and stable social relationship. The relationships between members of a core family will be the property of the expressive Guanxi (tie), which mostly satisfies each individual's need for care. However, people may also exercise the Guanxi (tie) to gain materials. In contrast to the expressive Guanxi (tie), the instrumental Guanxi (tie) refers to the social relationship between family members and individuals outer of the family, frequently strangers. For such individuals, the instrumental Guanxi is a kind of tool, which can fulfill their needs in materials, such as shoes or cars and so on. It is, as a result, quite unsteady and short-term. Between the expressive and instrumental relationship is the mixed Guanxi (tie). People within this kind of Guanxi are accustomed to each other's lives. Nevertheless, the depth and extent of the mixed Guanxi (tie) are far less than the relationship between family members. Examples of mixed Guanxi (tie) are relationships among classmates, colleagues, old customers and so on (Fried, 1969; Jacobs, 1979). People hold the three types of Guanxi at the same time within their social network. Individuals build up their social networks, which enclose very completed interactions (Jacobs, 1979; Kapferer, 1969; Mitchell, 1969). The characteristic of a social network in Chinese society is that people need to use public activities, such as eating and drinking, to maintain the mixed Guanxi. When most of the people in the society follow the interactive manner, it becomes a kind of Guanxi culture.

The concept of Renqing can be explained in there ways: (1) Renqing shows the affective reactions of an individual dealing with different situations; (2) Renqing represents a resource that an individual can give to, or accept form, other people as a gift in the course of social interaction; and (3) Renqing implies the social norms by which one has to bear with the reason of living well with other people (Gabrenya \& Hwang, 1996; Chen, 2006). Renqing is also a characteristic concept in Chinese culture, in which it refers to individuals' emotional reactions when they manage different situations of daily life. These responses can be treated as a kind of resources, which can give to other person as gifts (Hwang 1987). The process of continued giving and returning generate increasing Renqing between individuals in an exchange relationship (Blau, 1964; Buckley et al., 2006; Chan, 2006; Homans, 1961; Kim \& Leung, 2007).

The implication of doing Reqing means that the needs of members of a social network are fulfilled without cost or a lesser price other than through instrumental Guanxi (i.e. the equality rule). In other words, Renqing is a kind of 'resource' to give or swap among the members of a social network. From the viewpoint of Resource-Based Theory, Chinese managers may build up multiple social networks as intangible assets, which will be a firm foundation of their core competence. Once they are on their way toward becoming managerial officers in their companies, these resources will be among their most important advantages. Under the game of giving and returning Renqing, one important rule is that givers expect receivers to pay back Renqing in the future. Without such an expectation, the giving becomes a kind of donation or charity. Giving Renqing usually costs time and money or resources. Consequently, a dilemma may arise regarding Renqing if the givers do not fulfill all of the needs of members in their social networks. In western companies, managers may exercise the equity rule through their authority. However, Chinese managers also play a role as Renqing givers, who may share out resources by the equality rule (Leung \& Chan 2003; Lu, 2012).

Hwang (1987) considered that the principle of giving Renqing is based upon the receiver's power or authority. As a result, members in the social networks with superior positions, more power, and greater resources may receive more Renqing. On the other hand, the members without resources are denied Renqing. For instance, as happens in Chinese society fairly often, manager A plays golf often with company boss. One day, the board of directors decides to promote a manager into the top-management team. According to the performance criteria, manager B should be in the first place. However, manager A asks the boss for Renqing. To accommodate manager A, the criteria may be adjusted to include other issues so the manager A obtains the promotion in the final. Recently, Zhou et al. (2015) examine the roles of Renqing and Guanxi as outcomes of relationship marketing investments by a sample of 218 questionnaire respondents sourcing from the database of China Purchasing Managers' Club. It is found that the Renqing and Guanxi are necessary determinants of customer 
loyalty in China.

\section{The Relationships among Justice Theory, Guanxi, and Renqing in the Great China Area}

Based on the theoretical expansion above, a research framework is shown in the Figures 1, and three hypotheses are stated as follow:

H1: Businessperson with instrumental Guanxi will apply the equity rule, which excludes Renqing giving and returning in the Great China Area.

H2: Businessperson with mixed Guanxi will apply the equality rule, which will request moderate Renqing giving and returning in the Great China Area.

H3: Businessperson with expressive Guanxi will apply the need rule, which will request strong Renqing giving and returning in the Great China Area.

\begin{tabular}{|c|c|c|}
\hline Guanxi & Justice Theory & Renqing \\
\hline $\begin{array}{ll}\text { 1. } & \text { Instrumental } \\
\text { 2. } & \text { Mixed } \\
\text { 3. } & \text { Expressive }\end{array}$ & $\begin{array}{ll}\text { 1. } & \text { Equity rule } \\
\text { 2. } & \text { Equality rule } \\
\text { 3. } & \text { Need rule }\end{array}$ & $\begin{array}{ll}\text { 1. } & \text { Giving } \\
\text { 2. } & \text { Returning }\end{array}$ \\
\hline
\end{tabular}

Figure 1. Relationship among justice theory, Guanxi, and Renqing

\section{Methods}

The hypotheses were tested using data collected from the samples of Japanese managers in Taiwan. Judgmental sampling procedure was applied (Judd et al., 1991). A number of 1214 questionnaires were mailed to the Japanese expatriates in Taiwan. This survey was followed up by one reminder as a result of limited time and costs. 205 useful questionnaires were collected (a return rate of 16.89\%), of which 190 are used in the analysis (an utilizable return rate of $15.65 \%$ ).

Variables of Guanxi and Renqing were measured by previously developed multi-item scales. Following Ang and Leong (2000), we measured three types of Guanxi by 9 questions. Second part of the questionnaire measures Renqing, which includes 3 questions developed by Leung and Chan (2003). Each of the questions in the questionnaire is answered on a 7-point Likert scale from $1=$ strongly disagree to $7=$ strongly agree. The questionnaire was adopted in an English version originally and then translated into Japanese and Chinese versions. Back-translated method was used in order to ensure item equivalence across the cultures (Usunier, 1998).

\section{Results}

The correlations and descriptive statistics of the variables are presented in Table 1. The inter-correlations among the central variables of the study were all below the 0.80 value indicates there is no multi-collinearity among these variables (Hair et al., 1995).

Table 1. Correlation matrix of variables $(\mathrm{N}=190)$

\begin{tabular}{|c|c|c|c|c|c|c|}
\hline Variables & $\mathrm{X} 1$ & $\mathrm{X} 2$ & $\mathrm{X} 3$ & $\mathrm{Y}$ & Mean & SD \\
\hline $\mathrm{X} 1$ : instrumental Guanx & 1 & & & & 6.20 & 0.68 \\
\hline X2: mixed Guanxi & $.465^{* *}$ & 1 & & & 5.32 & 0.93 \\
\hline X3: expressive Guanxi & $.341^{* *}$ & $.522^{* *}$ & 1 & & 5.09 & 0.86 \\
\hline Y: Renqing & $.169^{*}$ & $.395^{* *}$ & $.542^{* *}$ & 1 & 4.61 & 0.96 \\
\hline
\end{tabular}

Note. $* * \mathrm{p}<0.01, * \mathrm{p}<0.05$. 
Tables 1 display the correlations among the variables, means, and standard deviations for Japanese respondents. As shown in Table 2, hypotheses are all supported. Hypothesis 1 predicts that businessperson with instrumental Guanxi will apply the equity rule, which excludes Renqing giving and returning. The result shows instrumental Guanxi is not related to Renqing ( $\mathrm{t}=-1.133 ; \mathrm{p}=0.259)$, $\mathrm{H} 1$ is supported. Hypothesis 2 states businessperson with mixed Guanxi will apply the equality rule, which will request moderate Renqing giving and returning. The results indicate that mixed Guanxi is related with Renqing giving and returning $(\mathrm{t}=2.422 ; \mathrm{p}=0.016)$. $\mathrm{H} 2$ is supported. Hypothesis 3 suggests businessperson with expressive Guanxi will apply the need rule, which will request strong Renqing giving and returning. The result shows support for $\mathrm{H} 3(\mathrm{t}=6.578 ; \mathrm{p}=0.00)$.

Table 2. Regressions analysis results

\begin{tabular}{cccc}
\hline Variables & Beta $(\beta)$ & t-value & Sig. \\
\hline Intercept & & 2.801 & 0.006 \\
instrumental Guanxi & -0.078 & -1.133 & 0.259 \\
mixed Guanxi & 0.185 & 2.422 & 0.016 \\
expressive Guanxi & 0.472 & 6.578 & 0.000 \\
\hline
\end{tabular}

Note. Adjusted $\mathrm{R}^{2}=0.304 ; \mathrm{F}=28.548$.

\section{Conclusion}

This paper develops two conceptual frameworks, on the basis of Hwang's (1987) model and the Justice Theory and examines the frameworks by Japanese and Taiwanese managers. The model suggested that businesspersons may look for or strengthen their Guanxi (tie) by transforming three types of social ties. As a result, resource al-locators in Chinese society may distribute their powers to others with different social ties. Moreover, this study examines the relationships among the three types of social ties and Renqing giving and returning. Data collected form questionnaires completed by 190 Japanese expatriate and 167 Taiwanese managers in Taiwan. All the hypotheses are supported. Unexpectedly, instrumental Guanxi is negatively correlated with Renqing in the Taiwanese group. This finding indicates that businesspersons with instrumental Guanxi not only without renqing but also can damage their business interests.

An old Chinese saying says: The debt of Renqing is very difficult to return. This is true primarily because it depends upon how much and what kind of Renqing a person receives. Renqing is an abstract concept, which is difficult to measure and classify. This study builds up a conceptual framework to link Guanxi, Renqing and Justice Theory. Moreover, three hypotheses are all supported. Leung et al. (2008) suggest that expatriates doing business in China need to transfer themselves from strangers into in-group of their Chinese counterparts.

Chua et al. (2009) found that the indirect social ties appear to have a bigger role for Chinese than for American managers. Consider the case discussed above, in which A in the ABC Company received Renqing form A's classmate, B, in the XYZ Company. One day, A has to pay back B. Wong et al. (2005) utilized Justice Theory to explain employees' responses to job insecurity in the Chinese context. They argue that joint ventures (JVs) and state-owned enterprises (SOE) are characterized by different kinds of employee-employer exchange and workers respond differently to job insecurity in these different types of organizations. By a number of 548 samples, it is found that the effects of job insecurity on organizational citizenship behavior (OCB) and job performance depend on organizational types. Further research can focus on the changing process of the three kinds of Gaunxi. On the other hand, Berger et al. (2015) found that western businesspersons view Guanxi and Renqing are important when they do business with their Chinese counterparts. Can western businesspersons practice Guanxi and Renqing well when they do business in China? It may be a raising topic for scholars in the field of cross-cultural research.

\section{References}

Ang, S., \& Leong, S. (2000). Out of the mouths of babes: Business ethics and youths in Asia. Journal of Business Ethics, 28(2), 129-144. http://dx.doi.org/10.1023/A:1006225330894

Berger, R., Herstein, R., Silbiger, A., \& Barnes, B. (2015). Can guanxi be created in Sino-Western relationships? An assessment of Western firms trading with China using the GRX scale. Industrial Marketing Management, 47, 166-174. http://dx.doi.org/10.1016/j.indmarman.2015.02.039 
Blau, P. M. (1964). Exchange and power in social life. NY: Wiley.

Buckley, P., Clegg, J., \& Tan, H. (2006). Cultural awareness in knowledge transfer to China-The role of guanxi and mianzi. Journal of World Business, 41(3), 275-288. http://dx.doi.org/10.1016/j.jwb.2006.01.008

Chan, A. (2006). The Chinese concepts of Guanxi, Mianzi, Renqing and Bao: Their Interrelationships and implications for international business. Australian \& New Zealand Marketing Academy (ANZMAC) Conference 2006, Brisbane, Australia.

Chua, R. Y. J., Morris, M. W., \& Ingram, P. (2009). Guanxi vs networking: Distinctive configurations of affect-and cognition-based trust in the networks of Chinese vs American managers. Journal of International Business Studies, 40(3), 490-508. http://dx.doi.org/10.1057/palgrave.jibs.8400422

Fei, X. (1992). From the soil: The foundations of Chinese society (Xiangtu Zhongguo). LA: University of California Press.

Fried, M. H. (1969). The fabric of Chinese society: A study of the social life of a Chinese county seat. NY: Octagon.

Gabrenya, Jr. W. K., \& Hwang, K. K. (1996). Chinese social interaction: Harmony and hierarchy on the good earth. In M. H. Bond (Ed.), The handbook of Chinese psychology (pp. 309-321). Hong Kong: Oxford University Press.

Hair, J. F. Jr., Anderson, R. E., Tatham, R. L., \& Black, W. C. (1995). Multivariate data analysis (3rd ed.). New York: Macmillan Publishing Company.

Homans, G. G. (1961). Social behavior: Its elementary forms. NY: Harcourt Brace.

Hwang, K. (1987). Face and favor: The Chinese power game. American Journal of Sociology, 92(4), 944-974. http://dx.doi.org/10.1086/228588

Jacobs, B. J. (1979). A preliminary model of particularistics ties in Chinese political alliances: 'Renqing' and 'Guanxi' in a rural Taiwanese township. China Quarterly, 78(2), 237-273. http://dx.doi.org/10.1017/S0305741000040467

Judd, C. M., Smith, E. R., \& Kidder, L. H. (1991). Research methods in social relation. Fort Worth, Holt: Rinehart and Winston.

Kapferer, B. (1969). Norms and the manipulation of relationships in a work context. In J. C. Mitchell (Ed.), Social networks in urban situation (pp. 181-240). Manchester: Manchester University Press.

Kim, T., \& Leung, K. (2007). Forming and reacting to overall fairness: A cross-cultural comparison. Organizational Behavior \& Human Decision Processes, 104(1), 83-95. http://dx.doi.org/10.1016/j.obhdp.2007.01.004

Leung, T. K. P., \& Chan, R. Y. (2003). Face, favour and positioning-A Chinese power game. European Journal of Marketing, 37(11), 1575-1598. http://dx.doi.org/10.1108/03090560310495366

Leung, T. K. P., Heung, V. C. S., \& Wong, Y. H. (2008). Cronyism: One possible consequence of Guanxi for an insider: How to obtain and maintain it? European Journal of Marketing, 42(1), 23-34. http://dx.doi.org/10.1108/03090560810840899

Lu, L. (2012). Guanxi and Renqing: The roles of two cultural norms in doing business with Chinese managers. International Journal of Management, 29(2), 466-475.

Luo, Y. (1997). Guanxi and performance of foreign-invested enterprises in China: An empirical inquiry. Management International Review, 37(1), 51-70. Retrieved from http://www.jstor.org/stable/40228387

Mitchell, J. C. (1969). The concept and use of social networks, in social networks in urban situation. In J. C. Mitchell (Ed.), Social networks in urban situation (pp. 1-50). Manchester: Manchester University Press.

Tsang, E. W. K. (1998). Can Guanxi be a source of sustained competitive advantage for doing business in China. Academy of Management Executive, 12(2), 64-73. http://dx.doi.org/10.5465/AME.1998.650517

Tsui, A. S., \& Farth, J. L. (1997). Where Guanxi matters: Relational demography and Guanxi in the Chinese context. Work and Occupations, 24(1), 56-79. http://dx.doi.org/10.1177/0730888497024001005

Usunier, J. C. (1998). International and cross-cultural management research. London, UK: Sage.

Wong, Y. H., \& Chan, R. Y. (1999). Relationship marketing in China: Guanxi, favoritism and adaptation. Journal of Business Ethics, 22(2), 107-118. http://dx.doi.org/10.1023/A:1006077210425 
Wong, Y., Wong, C., Ngo, H., \& Lui, H. (2005). Different responses to job insecurity of Chinese workers in joint ventures and state-owned enterprises. Human Relations, 58(11), 1391-1418. http://dx.doi.org/10.1177/0018726705060243

Yan, Y. (1996). The culture of Guanxi in a North China village. The China Journal, 35(1), 1-25. http://dx.doi.org/10.2307/2950274

Yang, M. M. (1994). Gifts, favors and banquets: The art of social relationships in China. NY: Cornell University Press.

Yang, M. M. (2002). The resilience of Guanxi and its new deployments: A critique of some new Guanxi scholarship. The China Quarterly, 170, 459-476. http://dx.doi.org/10.1017/S000944390200027X

Zhou, X., Shi, G., Liu, M., \& Bu, H. (2015). The mediating roles of Renqing and Ganqing in Chinese relationship marketing. Nankai Business Review International, 6(2), 156-176. http://dx.doi.org/10.1108/NBRI-03-2014-0014

\section{Copyrights}

Copyright for this article is retained by the author(s), with first publication rights granted to the journal.

This is an open-access article distributed under the terms and conditions of the Creative Commons Attribution license (http://creativecommons.org/licenses/by/3.0/). 